$4^{\text {th }}$ International Meeting on Calcitonin Gene-Related Peptide (CGRP)

TheScientificWorld (2001) 1(S1), 14

ISSN 1532-2246; DOI 10.1100/tsw.2001.427

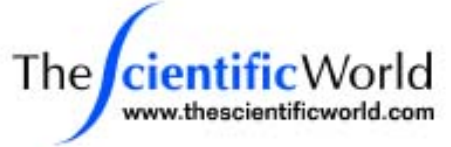

\title{
CGRP CHARACTERIZATION AND CLASSIFICATION
}

\author{
Ian Marshall \\ Department of Pharmacology, University College London, Gower Street, London, WC1E 6BT, \\ U.K.
}

The peptide CGRP is thought to be an agonist at a number of receptors including its own as well as those for adrenomedullin and amylin. CGRP is thought to act through its own receptors if it is antagonized by the truncated peptide $\mathrm{CGRP}_{8-37}$ although this assumes the specificity of the antagonist.

The subdivision of CGRP receptors by Quirion and colleagues into two types was based on use of a "selective" agonist, Cys $\left(\mathrm{ACM}^{2,7}\right) \mathrm{CGRP}$, and on truncated fragments of CGRP itself which were antagonists with varying potency in different systems. Most recently CRLR and RAMPs have been identified and provide a different perspective on CGRP receptors. It appears difficult to reconcile all these findings. Some of the issues include:

- - To what extent may the original CGRP1/2 subdivision be influenced by species differences in receptors?

- - Is Cys $\left(\mathrm{ACM}^{2,7}\right) \mathrm{CGRP}$ a "selective” agonist or a partial agonist and therefore of little use for receptor classification?

- - If there are only two CGRP subtypes why is there a range of 100 -fold in the antagonist potency CGRP $_{8-37}$ in different functional experiments even within a single species?

- - Why is the affinity of CGRP ${ }_{8-37}$ generally higher in experiments with cells than in tissues?

- - Is CRLR and RAMP1 a CGRP receptor or the CGRP receptor?

- - What is the relationship between tissue CRLR and RAMP expression with CGRP receptors defined functionally?

- - What is the way forward in defining receptors in the CGRP family of peptides? 

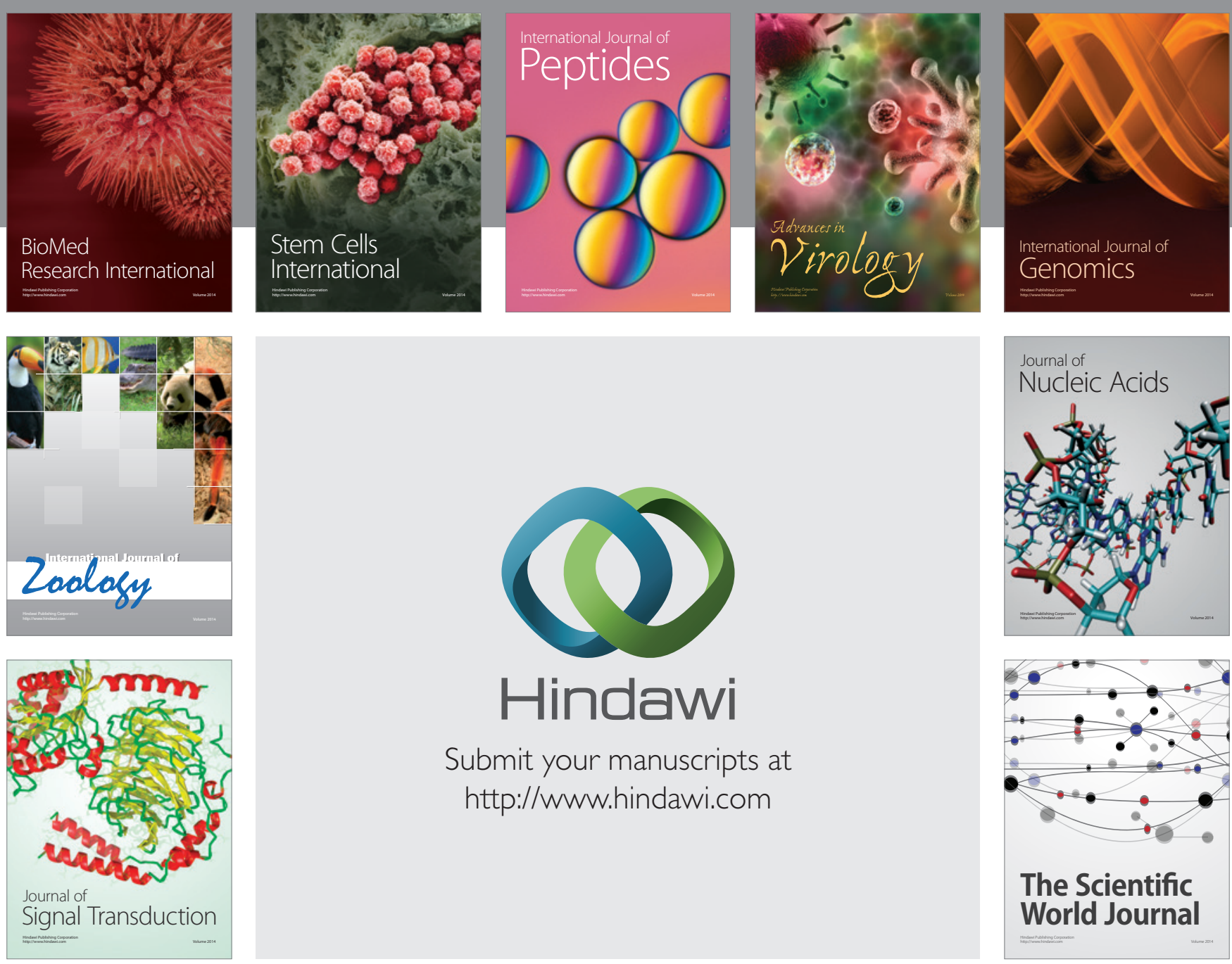

Submit your manuscripts at

http://www.hindawi.com
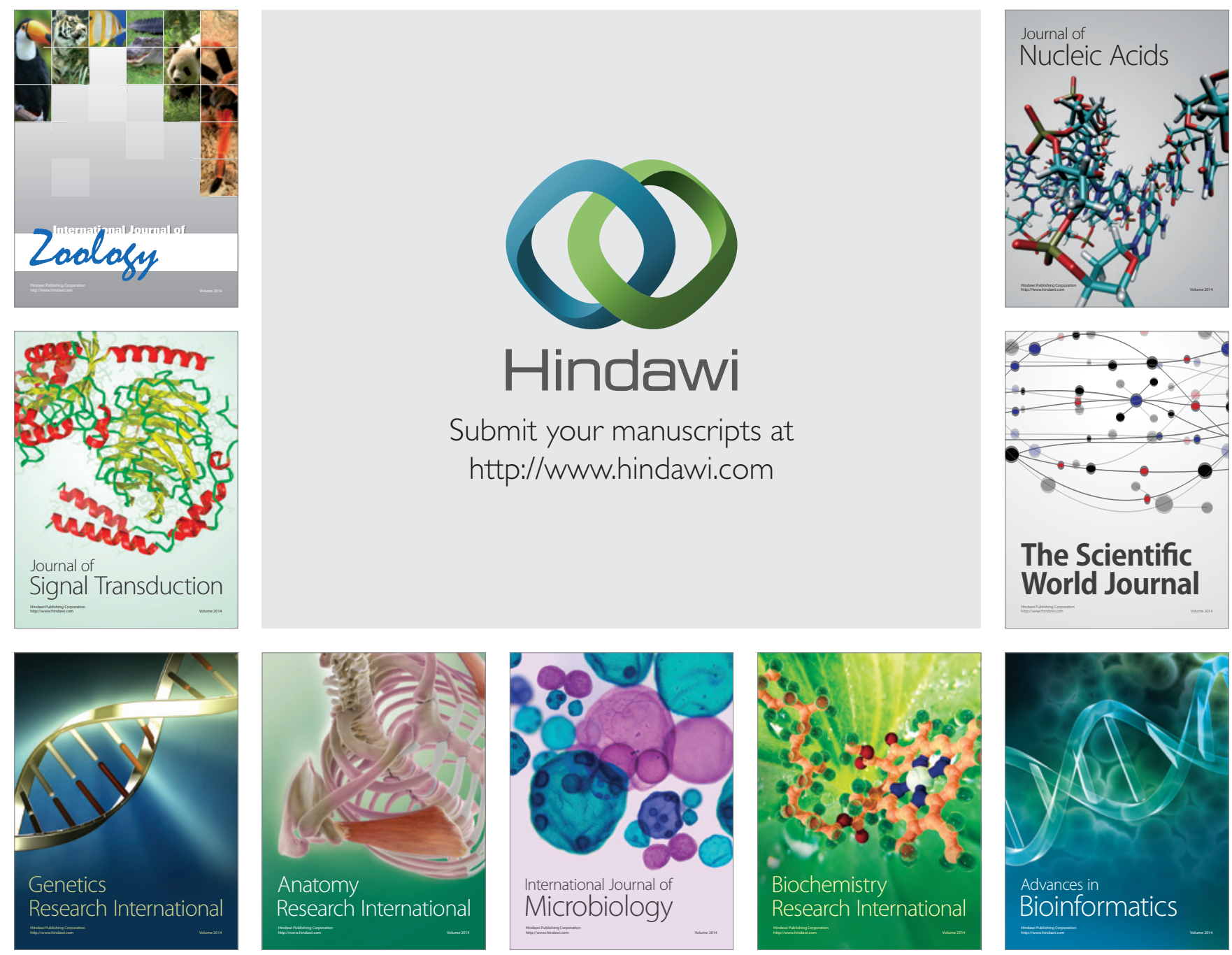

The Scientific World Journal
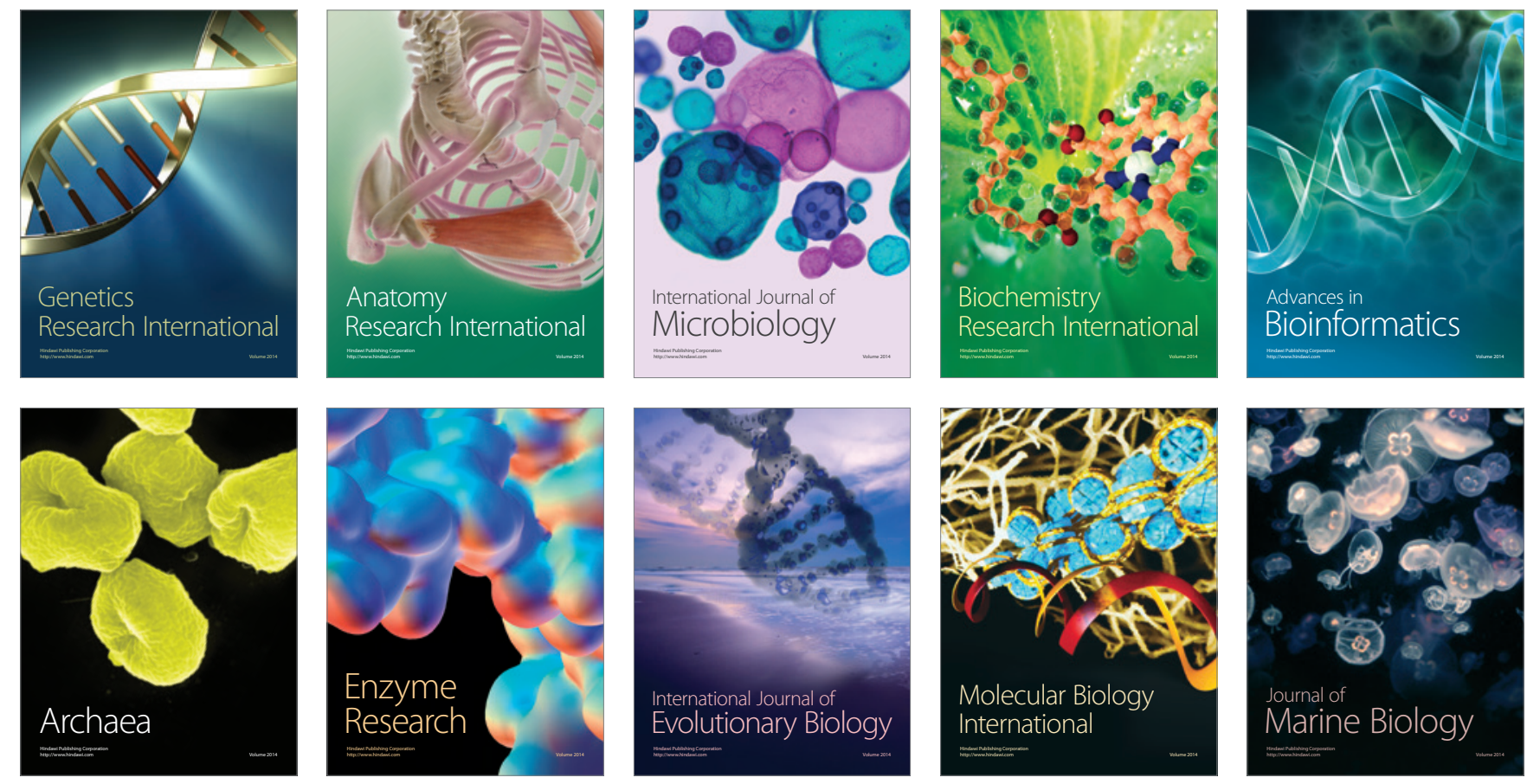